\title{
SEPARATION PERFORMANCE OF PVC AND PP PLASTIC MIXTURE USING AIR TABLE
}

\author{
G. DODBIBA ${ }^{\mathrm{a}, *}$, A. SHIBAYAMA ${ }^{\mathrm{a}}$, T. MIYAZAKI ${ }^{\mathrm{a}}$ and T. FUJITA ${ }^{\mathrm{a}, \mathrm{b}}$ \\ ${ }^{\mathrm{a}}$ Faculty of Engineering and Resource Science, Department of Material-process \\ Engineering and Applied Chemistry for Environment, Akita University, \\ Satellite Venture Business Laboratory (SVBL), 1-1 Tegata Gakuen-cho, \\ Akita 010-8502, Japan; ' Department of Geosystem Engineering, Graduate School of \\ Engineering, The University of Tokyo, Tokyo 113-8654, Japan
}

(Received 11 November 2002; In final form 14 January 2003)

\begin{abstract}
The aim of the research presented in this article was to investigate separation performance of the air table when separating a binary mixture of plastics. Separation using the air table, i.e. a dry mechanical process that grades constituents of the mixture with differences in specific gravity, is employed for separation of the PVC/PP mixture. Moreover, the performance of the laboratory-scale air table is improved by increasing the height of riffles laid on the porous deck.

The separation tests in a laboratory-scale air table showed that the total efficiency of the separation is mainly dependent on superficial velocity of the air, longitudinal vibrating frequency of the deck, end slope, side slope, and height of riffles. The respective influence of these variables upon the total efficiency of separation is demonstrated experimentally.

The evaluations of the separation performance for the two-component mixture are made in terms of grade $[\%]$, recovery $[\%]$ and total efficiency $[\%]$.
\end{abstract}

Keywords: Plastic separation; Air table; Separation efficiency; Height of riffles

\section{INTRODUCTION}

Plastic materials are gradually replacing metals as the main component in various products. The use of plastics by machine, electronic, packaging industries, etc is widespread. According to Japan Plastics Industry Federation [1], in Japan the production of plastic materials amounted to more than 14.7 million tones in 2000, while the production of polyvinyl chloride and polypropylene represented 16 and $18 \%$ of the total respectively. This in turn will inevitably increase the amount of plastic waste without considering recycling. Simple disposal of these waste compounds is wasteful and can be hazardous. Therefore, recycling is becoming a reasonable solution to the landfill problem.

*Corresponding author. E-mail: dodbiba@ipc.akita-u.ac.jp 
There are many kinds of plastics in wide use today including acrylonitrile-butadienestyrene (ABS), polyethylene terephthalate (PET), polyethylene (PE), polycarbonate (PC), polystyrene (PS), etc. Other common examples are the polyvinyl chloride (PVC) and polypropylene (PP) used in the packaging of products, vegetable oil bottles, medical field, etc.

Recently, steel companies in Japan have planned to utilize waste plastics instead of fine coal for charging into blast furnaces. This leads to the question of the long-term corrosion in furnace from increasing level of PVC in plastic wastes that can be used for that purpose. Furthermore, about two thirds of chlorine produced from incineration of PVC appears as hydrochloric acid in flue gas with the remainder being retained by ash [2]. Hence, the removal of PVC from other plastics should be carried out in advance.

Plastics separation technology has made good progress in developing different methods. Flotation [3-6], and sink-float [7,8] separation techniques are well known wet methods for plastic separation. Moreover, many kinds of plastics have been separated with high purity by electrostatic separation using friction mixer with rotary blades [9], tribo-cyclone [10], fluidized-bed triboelectrification [11], or vibrating feeder and electrostatic high voltage generator [12]. Additionally, the pneumatic separation, a dry mechanical process, is another method of separation. Pneumatic separation is not a recent discovery, as many patents can be found dating back as far as 1850 . They cover early attempts to separate materials of varying specific gravity or different shape by means of air [13].

Air tables or pneumatic tables [14], more than any other dry gravity concentrator have found their major applications particularly in food industry as they are originally developed for seed separation [15]. However, air tables have an important use in treatment of heavy minerals sand deposit [16,17], in cleaning of coal [18-20], in upgrading of tungsten [21], and in application where the water is at premium [22,23]. Being a dry method, separation using air table has a clear advantage over wet techniques because it requires less energy and no chemical pretreatment (such as in the case of flotation, sink-float separation, etc.). Furthermore, some potential problem associated with wet separating methods in general, such as treatment of water from the process for reuse or discharge, the requirement of expensive wetting reagents, and most importantly, dewatering the mixture after separation can be avoided.

The aim of this contribution is to investigate the performance of separation using the air table in order to obtain a high efficiency when separating PVC/PP plastic mixture. Consequently, the performance of the laboratory-scale air table is improved by adjusting the height of riffles laid on the porous deck.

\section{PRINCIPLES OF PNEUMATIC SEPARATION USING AIR TABLE}

The air table (manufactured by Triple/S Dynamics, Inc.; model No. V-135E) is mainly comprised of a hopper, a vibrating feeder, a porous deck powered by an eccentric drive to impart the longitudinal vibration and an electric fan located below the porous deck to generate the upward air flow at a controlled value of superficial velocity. A sketch of the experimental apparatus is shown in Fig. 1. A collecting bin is arranged alongside the discharge end of the separator (Fig. 1). It consists of two compartments separated by a splitter being positioned by preliminary visual assessments. 


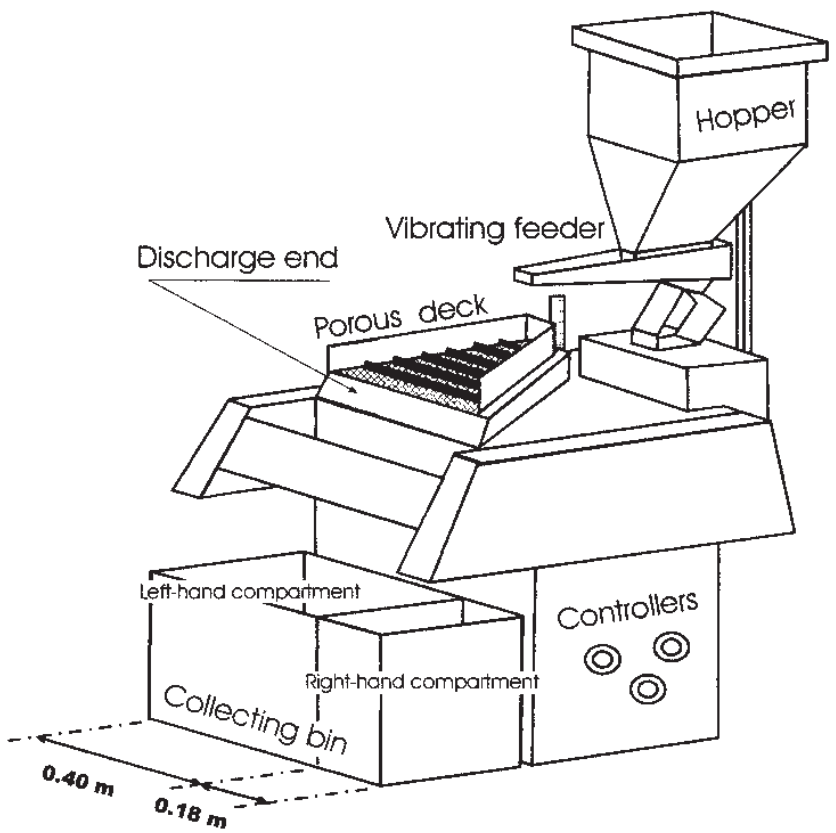

FIGURE 1 Schematic design of the laboratory-scale air table.

A flat trapezoidal deck constructed of wood and porous material is fitted with a perforated plate with circular openings (Opening area $=11.8 \%$ ) and with a series of riffles, $4.5 \mathrm{~mm}$ in height, arranged in parallel to the direction of the longitudinal vibration. The size of the openings, $0.06 \mathrm{~mm}$, is smaller than the size of the smallest particle in the mixture, disallowing particle falling through. The deck can be adjusted in transverse and longitudinal inclination. Thus, it can be tilted from the inlet end to the discharge end, i.e. "side slope", and from side to side, i.e. "end slope", (Fig. 2). Controllers, mounted near the deck, allowed adjusting of the end slope of the deck, side slope, longitudinal vibration frequency and superficial velocity of the air (Fig. 1). Not shown in Fig. 1 is a truncated pyramid-shaped hood of trapezoidal base, $0.14 \mathrm{~m}$ in height, suspended $0.25 \mathrm{~m}$ above the porous deck. The hood is employed to prevent the initial decrease of airflow close to the sides of the deck.

In an air table as well as in a fluidized bed or jig, the bed of particles is lifted by a fluid flow. Therefore, the movement of particle in an air table is similar to the movement of particle in a fluidized bed or jig.

When the superficial air velocity is zero, the particle weight is entirely supported by the deck. However, when the air is forced through the porous deck of the air table and the bed of particles, the bed expansion eventually occurs when the superficial velocity of the air reaches a so-called minimum fluidizing value. At this point the weight of the bed of particles is fully supported by the drag force produced by the air [24]. The superficial velocity of air at minimum fluidizing conditions, $u_{m f}$, for coarse particles is expressed as follows [25]:

$$
u_{m f}=\left(\frac{\mu}{d_{p} \cdot \rho_{g}}\right) \cdot\left\{\left[823.69+0.0494\left(\frac{d_{p}^{3} \cdot \rho_{g} \cdot\left(\rho_{s}-\rho_{g}\right) \cdot g}{\mu^{2}}\right)\right]^{1 / 2}-28.7\right\}
$$




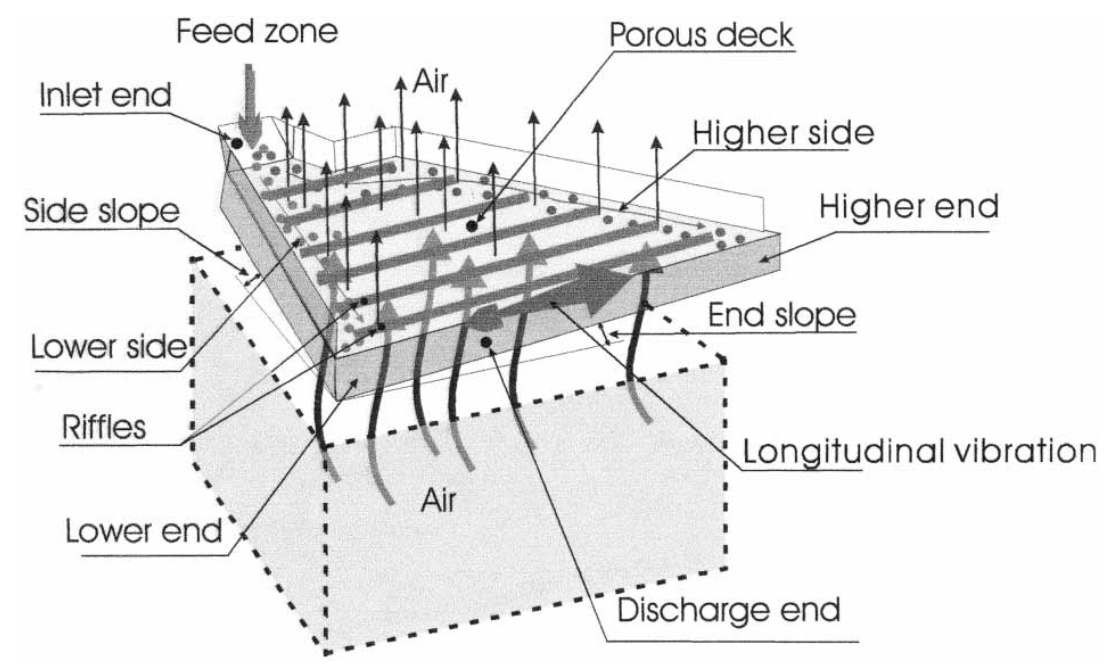

FIGURE 2 Schematic diagram illustrating the principle of separation by air table.

Refering to Eq. (1), it can be noted that the minimum fluidizing velocity depends on the size of particle, its density, density of air and air absolute viscosity.

To avoid the carryover of particles from the bed, the superficial velocity of air should be kept between the minimum fluidizing velocity, $u_{m f}$, and terminal velocity of the particles, $u_{t}$ [25]. In 1989, Haider et al. [26], presented the following Eq. (2) for direct evaluation of the terminal velocity of the particles, $u_{t}$ :

$$
u_{t}=u_{t}^{*}\left[\frac{\mu\left(\rho_{s}-\rho_{g}\right) g}{\rho_{g}^{2}}\right]^{1 / 3}
$$

where $u_{t}^{*}$ is defined as a dimensionless air velocity and calculated as follows:

$$
u_{t}^{*}=\left[\frac{18}{\left(d_{p}^{*}\right)^{2}}+\frac{2.335-1.744 \phi_{s}}{\left(d_{p}^{*}\right)^{0.5}}\right]^{-1} \quad 0.5<\phi_{s}<1
$$

Accordingly, $u_{t}^{*}$ (Eq. (3)) depends on $d_{p}^{*}$, a dimensionless particle size that is calculated by the Eq. (4):

$$
d_{p}^{*}=d_{p}\left[\frac{\rho_{g}\left(\rho_{s}-\rho_{g}\right) g}{\mu^{2}}\right]^{1 / 3}
$$

It can be noted that $u_{t}^{*}$ (Eq. (3)) is also related to a one-parameter measure called sphericity, $\phi_{S}$, defined as the ratio of the surface area of a sphere of volume equal to that of the particle, to the surface area of the particle $[25,27]$. Thus,

$$
\phi_{s}=\left[\frac{\text { surface area of sphere }}{\text { surface area of particle }}\right]_{\text {of same volume }}
$$

From the above definition of sphericity, it transpires that $\phi_{s}=1$ for spheres and $0<\phi_{s}<1$ for other particle shapes. 


\section{EXPERIMENTAL}

\subsection{Materials}

The experiments are carried out using 50/50\% artificial mixtures of polyvinyl chloride (PVC) and polypropylene (PP). Initially, the components of the mixture are chopped into flakes with a shredder provided by Nissui Kako Co. LTD of Japan (Nissui Scutter, type : SA-22), and classified by their size using conventional sieving. Plastic flakes of irregular shapes and approximately $-3.36+2.38 \mathrm{~mm}$ in size $(-6+8 \mathrm{mesh})$ are used throughout the experiment. The shape of the plastic flakes can be seen in Fig. 3 showing the photographs of the $-3.36+2.38 \mathrm{~mm}$ size fraction. The difference in color between plastic types allowed easy hand-sorting and analysis of the collected fractions.

Table I tabulates each plastic component with its physical properties. Flake diameter is determined by screen analysis, whereas density, $\rho_{s}$, is measured using pycnometer and ethanol (density of $790 \mathrm{~kg} / \mathrm{m}^{3}$ ) as the relative substance.

The experiments are performed in a "batch mode" of operation with the apparatus shown in Figs. 1 and 2. During each test, a plastic sample from the same source is used. The mass of the processed samples was approximately $0.20 \mathrm{~kg}$.

\subsection{Experimental Procedure}

In operation, initially the particles of similar size are discharged from a hopper and then fed by a vibrating feeder onto the deck, creating a uniform bed of material over

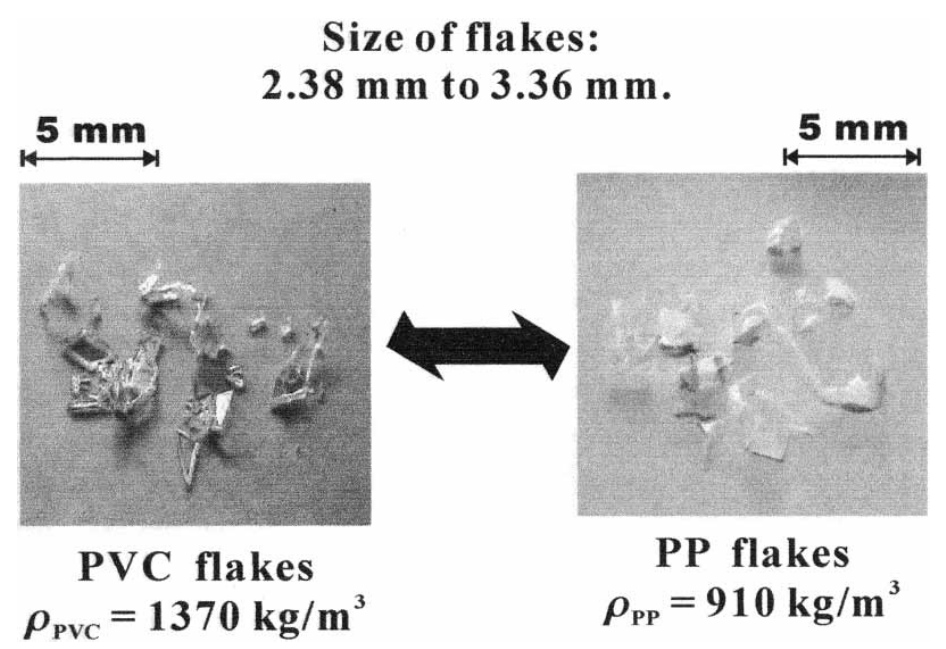

FIGURE 3 Plastic components of the artificial mixture.

TABLE I Properties of the plastic components of the investigated mixture

\begin{tabular}{lccc}
\hline Polymer type & Size of flakes $[\mathrm{mm}]$ & Density, $\rho_{s}\left[\mathrm{~kg} / \mathrm{m}^{3}\right]$ & Colour \\
\hline PVC & $-3.36+2.38$ & 1370 & Colourless \\
PP & $-3.36+2.38$ & 910 & Yellow \\
\hline
\end{tabular}


the deck surface. The eccentric drive vibrates the deck in a side-to-side motion, along the direction of riffles, at a frequency from 0.09 to $13.33 \mathrm{~s}^{-1}$ (typically, about 6.21 to $12.55 \mathrm{~s}^{-1}$ ) with corresponding stroke length of $4.5 \mathrm{~mm}$. Simultaneously, an electric fan blows air upward through the porous decks at a superficial velocity of from 1 to $4 \mathrm{~m} / \mathrm{s}$ (Fig. 2). The longitudinal vibrating frequency of the deck and its stroke length are measured by a laser type displacement sensor (Type: Keyence LB Series), whereas the superficial velocity of air is controlled by the electric voltage input of the electric fan and is measured using an anemometer (Sibata, Windman I SA-62).

The longitudinal vibration and airflow spreads and lifts the entire material bed on the surface of the deck; then, as the material bed falls, it is expanded and fluidized. The material stratified according to specific gravity, causing the "heavier particles" to settle on the deck and contact its surface, while the "lighter particles" to float on top of the "heavier particles". As the eccentric drive vibrates the deck using a slow forward stroke and a rapid return, the "heavier particles" move along the deck between the riffles up the end slope towards the higher side (Fig. 2) Subsequently, the "heavier particles" are flowed off the deck through the higher side, which channels them downward to the discharge end, and are dropped into the right-hand compartment of collecting bin (Figs. 1 and 2). On the other hand, the "lighter particles", which remain fluidized, drift downhill in the direction of the deck's inclination due to gravitational pull and are discharged at the deck's lower end or overflow the riffles and drop into the left-hand compartment of the collecting bin (Figs. 1 and 2).

\subsection{Evaluations of the Separation Performance}

At the end of each experiment, the individual separated fractions are collected and weighed. Then, the evaluations of the separation performance for the two-component mixture are made in terms of the grade [\%] and the recovery [\%]. These terms are defined as follows:

$$
\begin{gathered}
\text { Grade }_{A}=\frac{\text { Mass of material } A \text { in the collected fraction }}{\text { Total mass of the collected fraction }} \times 100 \% \\
\text { Recovery }_{A}=\frac{\text { Mass of material } A \text { in the collected fraction }}{\text { Total Mass of material } A \text { in feed stream }} \times 100 \%
\end{gathered}
$$

where " $A$ " denotes one of the components of the mixture.

Because of inconvenience and difficulty in using two measures of the separation performance (i.e. grade and recovery), and in order to adequately define the performance of the separator, some efforts have been directed towards the development of a single-value parameter supposing that the separator, produces only two output streams [28,29]. In 1957, Rietema [30], recommended that the total efficiency, $E[\%]$, of the separation process can be obtained from:

$$
E=\left|\frac{\text { Weight of product } A \text { in stream } 1}{\text { Weight of product } A \text { in feed }}-\frac{\text { Weight of product } B \text { in stream } 1}{\text { Weight of product } B \text { in feed }}\right| \times 100 \%
$$


or

$E=\left|\frac{\text { Weight of product } A \text { in stream } 2}{\text { Weight of product } A \text { in feed }}-\frac{\text { Weight of product } B \text { in stream } 2}{\text { Weight of product } B \text { in feed }}\right| \times 100 \%$

where " $A$ " or " $B$ " denotes one of the components of the mixture.

Moreover, in 1979, Worrel et al. [31], expressed the total efficiency as follows:

$E=\left(\frac{\text { Weight of product } A \text { in stream } 1}{\text { Weight of product } A \text { in feed }}\right) \times\left(\frac{\text { Weight of product } B \text { in stream } 2}{\text { Weight of product } B \text { in feed }}\right) \times 100 \%$

In this work, Eq. (10), which relies on the mass balance between the incoming and exiting fractions, is used for the calculation of the total efficiency.

\section{EXPERIMENTAL RESULTS AND DISCUSSIONS}

Although the separation using air table seems simple, there are many variables affecting its performance. Therefore the study of performance of the air table and its optimization is not an easy task. A set of experiments is concerned with developing an understanding of the influence of varying superficial velocities of the air, longitudinal vibrating frequency, end slope, side slope or height of riffles respectively. Consequently, the respective effect of these variables upon the separation efficiency is demonstrated experimentally.

During each run, a splitter cuts the product stream at the discharge end producing only two fractions. Thus, part of the product stream, i.e. "lighter fraction", is allowed to report into the left-hand compartment of the collecting bin, while the remaining part i.e. "heavier fraction" is channeled into the right-hand compartment (Figs. 1 and 2).

\subsection{The Influence of the Superficial Air Velocity}

In this series of tests the superficial air velocity is the variable and ranges from 1.1 to $2.8 \mathrm{~m} / \mathrm{s}$. The other variables of the operations are kept constant at the following

TABLE II Separation results of PP from PVC. Superficial air velocity the variable (Experimental conditions: PVC/PP mixture $(50 / 50 \%)$; flake size $=-3.36+2.38 \mathrm{~mm}$; longitudinal vibrating frequency $=11.95 \mathrm{~s}^{-1}$; end slope $=4.5^{\circ}$; side slope $=2.5^{\circ}$; height of riffles $=7 \mathrm{~mm}$ )

\begin{tabular}{ccccccc}
\hline Test no. & $\begin{array}{c}\text { Superficial } \\
\text { air velocity } \\
{[\mathrm{m} / \mathrm{s}]}\end{array}$ & \multicolumn{2}{c}{$\begin{array}{c}\text { PP fraction } \\
\text { left-hand compartment }\end{array}$} & & \multicolumn{2}{c}{$\begin{array}{c}\text { PVC fraction } \\
\text { right-hand compartment }\end{array}$} \\
& & Grade [\%] & Recovery $[\%]$ & & Grade [\%] & Recovery [\%] \\
\hline 83 & 1.1 & 96.91 & 7.81 & & 45.83 & 94.21 \\
112 & 1.4 & 99.05 & 56.33 & & 88.09 & 94.43 \\
110 & 1.8 & 95.84 & 96.70 & & 99.90 & 97.70 \\
79 & 2.2 & 95.25 & 96.57 & & 94.01 & 69.46 \\
80 & 2.5 & 79.72 & 97.97 & & 94.60 & 31.28 \\
81 & 2.8 & 68.21 & 98.82 & & 91.84 & 12.00 \\
\hline
\end{tabular}




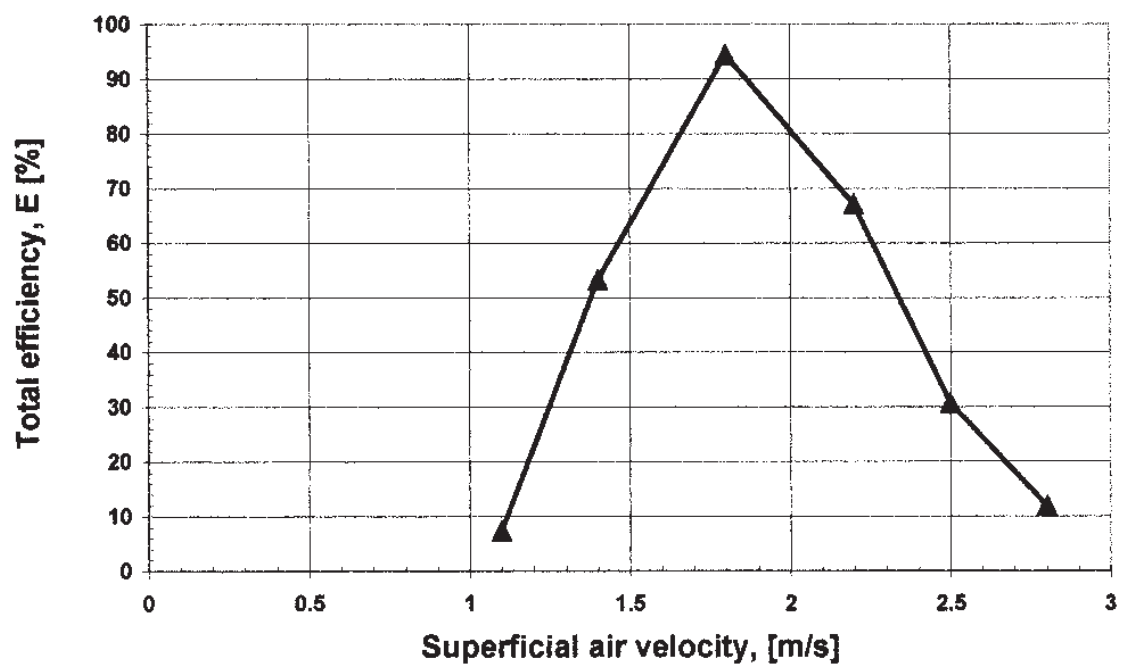

FIGURE 4 Total separation efficiency of PVC/PP mixture $(50 / 50 \%)$, showing the effect of superficial air velocity (Experimental conditions: flake size $=-3.36+2.38 \mathrm{~mm}$; longitudinal vibrating frequency $=11.95 \mathrm{~s}^{-1}$; end slope $=4.5^{\circ}$; side slope $=2.5^{\circ}$; height of riffles $=7 \mathrm{~mm}$ ).

values: longitudinal vibrating frequency of the deck, $11.95 \mathrm{~s}^{-1}$; end slope, $4.5^{\circ}$; side slope, $2.5^{\circ}$; height of riffles, $7 \mathrm{~mm}$. Table II gives the numerical results of the tests.

Data plotted in Fig. 4 demonstrate that variation of superficial velocity of air influences noticeably the total efficiency of separation. The higher the velocity of air, the higher is the recovery of PP flakes and the lower is the recovery of PVC ones, as more PVC flakes are suspended above the deck and discharged at the left-hand compartment of collecting bin contaminating the PP fraction (Table II). It is importance to note that the velocity of air higher than $3 \mathrm{~m} / \mathrm{s}$ tends to raise all the flakes off the deck, destroying any stratification effect and makes the separation of the mixture an extremely difficult task. On the contrary, the lower the velocity of air, the higher is the recovery of PVC flakes and the higher is the grade of PP ones (Table II). However, superficial air velocity less than $1 \mathrm{~m} / \mathrm{s}$ causes the bed of plastic flakes to be sluggish and to accumulate at the higher end of the deck.

Referring to the data illustrated in Fig. 4, the highest separation efficiency is achieved at the superficial air velocity of $1.8 \mathrm{~m} / \mathrm{s}$. In addition, the experimental results suggest that the best separating conditions are provided when the superficial air velocity is higher than the velocity of air required for minimum fluidizing conditions of "heavier flakes". This can be calculated using Eq. (1).

\subsection{The Influence of the Longitudinal Vibrating Frequency of the Deck}

The influence of varying the longitudinal vibrating frequency of the deck on the total efficiency of separations is studied by ranging the longitudinal vibrating frequency from 6.21 to $12.55 \mathrm{~s}^{-1}$, with the corresponding stroke length of $4.5 \mathrm{~mm}$. The other operating variables are maintained at the following constant values: superficial air velocity, $1.8 \mathrm{~m} / \mathrm{s}$; end slope, $4.5^{\circ}$; side slope, $2.5^{\circ}$; height of riffles, $7 \mathrm{~mm}$. Values of the total efficiency corresponding to the separation at various vibrating frequencies shown in Fig. 5 are listed in Table III. 


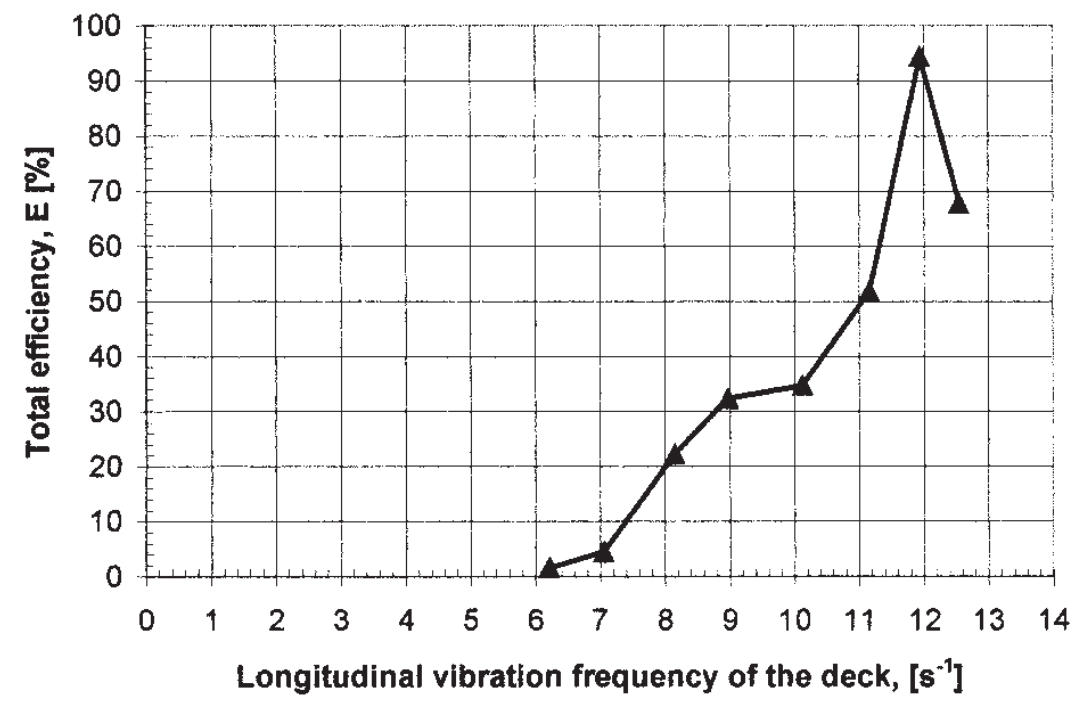

FIGURE 5 Total separation efficiency of PVC/PP mixture (50/50\%), showing the effect of longitudinal vibration frequency of deck (Experimental conditions; flake size $=-3.36+2.38 \mathrm{~mm}$; superficial air velocity $=1.8 \mathrm{~m} / \mathrm{s}$; end slope $=4.5^{\circ}$; side slope $=2.5^{\circ}$; height of riffles $=7 \mathrm{~mm}$ ).

TABLE III Separation results of PP from PVC. Longitudinal vibrating frequency the variable (Experimental conditions: PVC/PP mixture $(50 / 50 \%)$; flake size $=-3.36+2.38 \mathrm{~mm}$; superficial air velocity $=1.8 \mathrm{~m} / \mathrm{s}$; end slope $=4.5^{\circ} ;$ side slope $=2.5^{\circ}$; height of riffles $=7 \mathrm{~mm}$ )

\begin{tabular}{|c|c|c|c|c|c|}
\hline \multirow[t]{2}{*}{ Test no. } & \multirow{2}{*}{$\begin{array}{c}\text { Vibrating } \\
\text { frequency } \\
\quad\left[\mathrm{s}^{-1}\right]\end{array}$} & \multicolumn{2}{|c|}{$\begin{array}{c}P P \text { fraction } \\
\text { left-hand compartment }\end{array}$} & \multicolumn{2}{|c|}{$\begin{array}{c}P V C \text { fraction } \\
\text { right-hand compartment }\end{array}$} \\
\hline & & Grade [\%] & Recovery $[\%]$ & Grade $[\%]$ & Recovery $[\%]$ \\
\hline 91 & 6.21 & 68.69 & 88.12 & 32.29 & 1.86 \\
\hline 90 & 7.05 & 93.40 & 86.87 & 50.42 & 5.15 \\
\hline 89 & 8.15 & 94.84 & 88.97 & 74.95 & 25.04 \\
\hline 88 & 8.97 & 96.83 & 91.97 & 77.01 & 35.11 \\
\hline 87 & 10.12 & 96.82 & 92.16 & 84.15 & 37.67 \\
\hline 86 & 11.16 & 96.99 & 94.13 & 92.22 & 55.07 \\
\hline 110 & 11.95 & 95.84 & 96.70 & 99.90 & 97.70 \\
\hline 108 & 12.55 & 87.03 & 97.51 & 98.90 & 72.58 \\
\hline
\end{tabular}

Considering the results, no separation is observed at the longitudinal vibrating frequency of less than $7.05 \mathrm{~s}^{-1}$, as the PVC flakes in contact with the deck shift towards the lower side and discharge to the left-hand compartment (Table III and Fig. 5). Moreover, an increase in vibrating frequency tends to direct the PVC flakes, closest to the deck, towards the higher side of the deck. However, when the vibrating frequency is higher than $11.95 \mathrm{~s}^{-1}$ no improvement on total efficiency of separation is observed (Fig. 5). This is due to the fact that at higher frequencies the jump heights of the flakes in contact with the deck is increased. This in turn causes that more PVC flakes overflow the riffles and contaminate the collected light fraction of PP. The data tabulated in Table III demonstrate that the influence of the vibrating frequency on the recovery of PP flakes is irrelevant, as those flakes are not in direct contact with the surface of the deck, due to the fluidizing effect of the upward airflow. It can be concluded that the longitudinal vibrating frequency of the deck has a pronounced 
influence on the total efficiency of separation. Referring to the results, the highest total efficiency is achieved at a vibrating frequency of $11.95 \mathrm{~s}^{-1}$ (Fig. 5).

\subsection{The Influence of the Slope of the Deck (End Slope and Side Slope)}

The effect of the end slope (Fig. 2) studied over a range of $2.5-5^{\circ}$, with other variables held constant at the following values: superficial air velocity, $1.8 \mathrm{~m} / \mathrm{s}$; longitudinal vibrating frequency of the deck, $11.95 \mathrm{~s}^{-1}$; slide slope 2.5 degrees, $\left[{ }^{\circ}\right]$; height of riffles, $7 \mathrm{~mm}$.

Table IV shows the summary of experimental results of the tests. An end slope higher than $4.5^{\circ}$ decreases the grade of the collected PP, as more PVC flakes are directed towards the lower side of the deck and discharged at the left-hand compartment of collecting bin contaminating the PP fraction (Table IV). On the contrary, the lower the end slope, the higher is the recovery of PVC flakes (Table IV), as more flakes are directed towards the higher side of the deck (Fig. 2). However, an end slope lower

TABLE IV Separation results of PP from PVC. End slope the variable (Experimental conditions: PVC/PP mixture $(50 / 50 \%)$; flake size $=-3.36+2.38 \mathrm{~mm}$; superficial air velocity $=1.8 \mathrm{~m} / \mathrm{s}$; longitudinal vibration frequency $=11.95 \mathrm{~s}^{-1}$; side slope $=2.5^{\circ}$; height of riffles $=7 \mathrm{~mm}$ )

\begin{tabular}{|c|c|c|c|c|c|}
\hline \multirow[t]{2}{*}{ Test no. } & \multirow[t]{2}{*}{$\begin{array}{c}\text { End slope } \\
{\left[{ }^{\circ}\right]}\end{array}$} & \multicolumn{2}{|c|}{$\begin{array}{c}\text { PP fraction } \\
\text { left-hand compartment }\end{array}$} & \multicolumn{2}{|c|}{$\begin{array}{c}\text { PVC fraction } \\
\text { right-hand compartment }\end{array}$} \\
\hline & & Grade [\%] & Recovery [\%] & Grade [\%] & Recovery [\%] \\
\hline 112 & 2.5 & 96.95 & 64.22 & 80.59 & 98.59 \\
\hline 113 & 3.0 & 97.13 & 70.92 & 93.61 & 98.04 \\
\hline 114 & 3.5 & 96.41 & 72.17 & 93.15 & 98.00 \\
\hline 111 & 4.0 & 96.70 & 87.77 & 98.11 & 97.91 \\
\hline 110 & 4.5 & 95.84 & 96.70 & 99.90 & 97.70 \\
\hline 115 & 5.0 & 87.48 & 99.63 & 99.74 & 57.16 \\
\hline
\end{tabular}

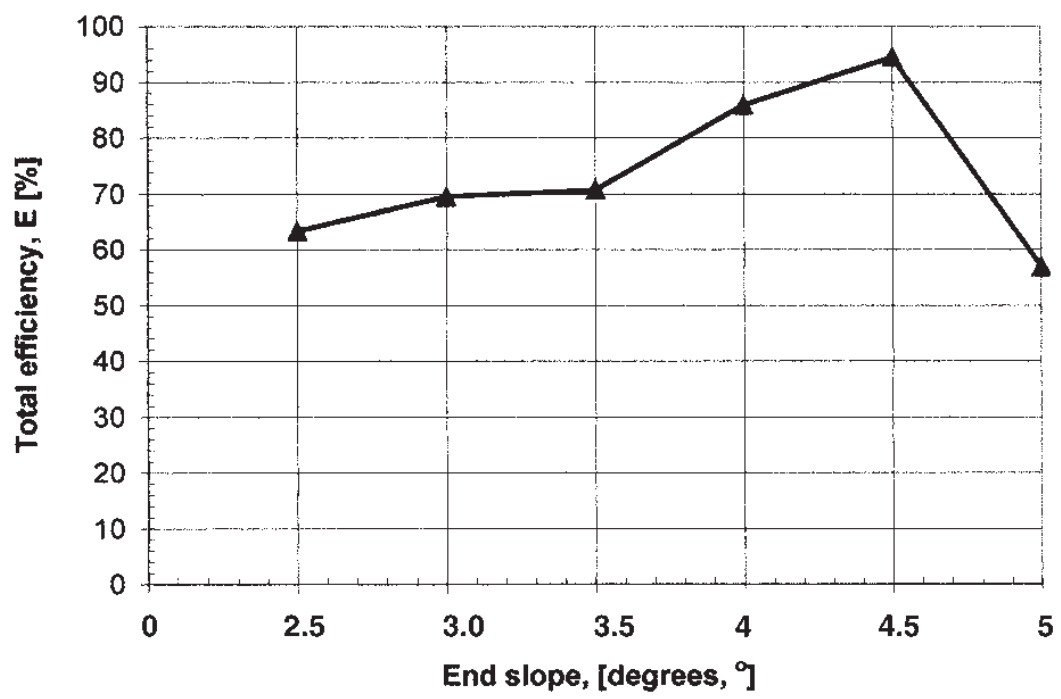

FIGURE 6 Total separation efficiency of PVC/PP mixture (50/50\%), showing the effect of end slope (Experimental conditions: flake size $=-3.36+2.38 \mathrm{~mm}$; superficial air velocity $=1.8 \mathrm{~m} / \mathrm{s}$; longitudinal vibration frequency $=11.95 \mathrm{~s}^{-1}$; side slope $=2.5^{\circ}$; height of riffles $=7 \mathrm{~mm}$ ). 
than $3.5^{\circ}$ causes the plastic flakes settled on the deck to be accumulated at the higher end of the deck and destroyed the separation process. Generally, changes in end slope indicate that the end slope affects, to a large extent, the direction of travel of the flakes in contact with the deck surface. Figure 6 depicts a plot of the total efficiency against the end slope of the deck (i.e. PVC). It shows that the highest efficiency is achieved when the end slope is set at $4.5^{\circ}$.

Subsequently, Table V and Fig. 7 present the experimental results from a series of tests in which the side slope is varied from 1.9 to $8.5^{\circ}$, while the other variables are kept constant at the following values: superficial air velocity, $1.8 \mathrm{~m} / \mathrm{s}$; longitudinal vibration frequency of the deck, $11.95 \mathrm{~s}^{-1}$; end slope, $4.5^{\circ}$; height of riffles, $7 \mathrm{~mm}$.

TABLE V Separation results of PP from PVC. Side slope the variable (Experimental conditions: PVC/PP mixture $(50 / 50 \%)$; flake size $=-3.36+2.38 \mathrm{~mm}$; superficial air velocity $=1.8 \mathrm{~m} / \mathrm{s}$; longitudinal vibration frequency $=11.95 \mathrm{~s}^{-1}$; end slope $=4.5^{\circ}$; height of riffles $=7 \mathrm{~mm}$ )

\begin{tabular}{|c|c|c|c|c|c|}
\hline \multirow[t]{2}{*}{ Test no. } & \multirow[t]{2}{*}{$\begin{array}{c}\text { Side slope } \\
{\left[{ }^{\circ}\right]}\end{array}$} & \multicolumn{2}{|c|}{$\begin{array}{c}\text { PP fraction } \\
\text { left-hand compartment }\end{array}$} & \multicolumn{2}{|c|}{$\begin{array}{c}P V C \text { fraction } \\
\text { right-hand compartment }\end{array}$} \\
\hline & & Grade [\%] & Recovery $[\%]$ & Grade [\%] & Recovery [\%] \\
\hline 54 & 1.9 & 88.68 & 95.15 & 93.60 & 68.55 \\
\hline 98 & 2.3 & 90.46 & 95.22 & 94.69 & 71.61 \\
\hline 110 & 2.5 & 95.84 & 96.70 & 99.90 & 97.70 \\
\hline 99 & 3.5 & 80.18 & 97.98 & 95.50 & 44.63 \\
\hline 100 & 4.5 & 72.94 & 98.87 & 96.18 & 20.28 \\
\hline 101 & 5.0 & 71.40 & 98.36 & 96.91 & 8.31 \\
\hline 102 & 6.0 & 71.71 & 98.21 & 97.14 & 8.23 \\
\hline 103 & 7.0 & 68.50 & 99.65 & 97.44 & 8.12 \\
\hline 104 & 8.0 & 66.74 & 98.73 & 97.88 & 7.92 \\
\hline 105 & 8.5 & 64.69 & 99.48 & 97.98 & 7.66 \\
\hline
\end{tabular}

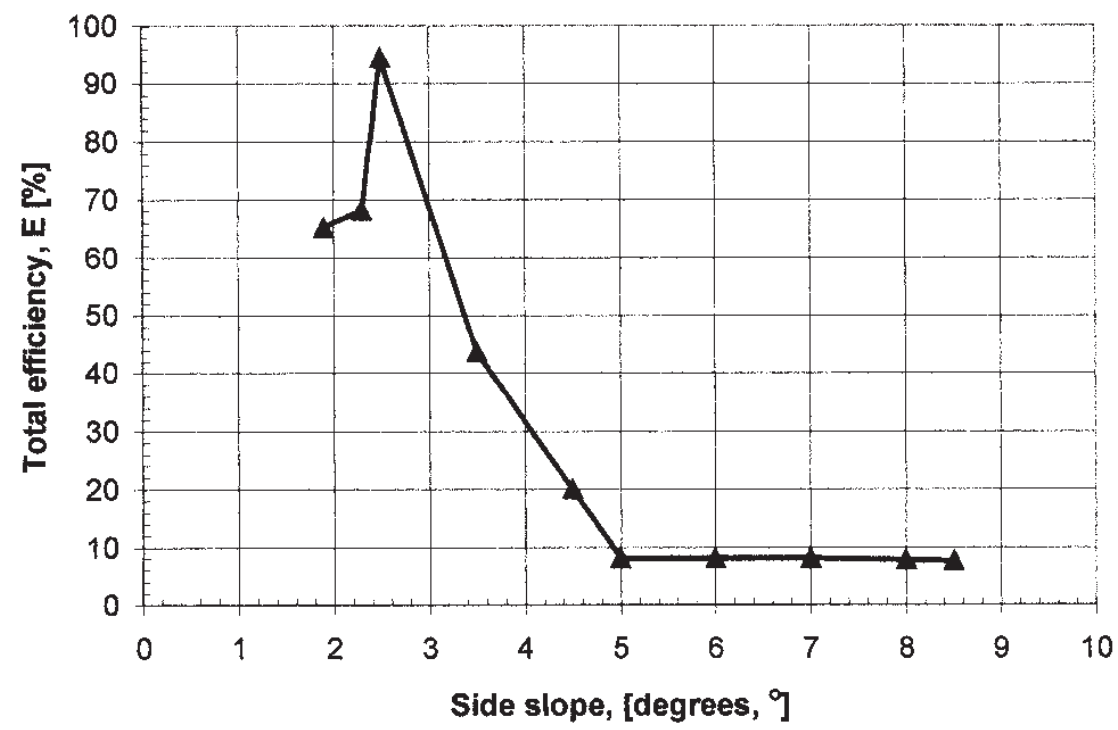

FIGURE 7 Total separation efficiency of PVC/PP mixture (50/50\%), showing the effect of side slope (Experimental conditions: flake size $=-3.36+2.38 \mathrm{~mm}$; superficial air velocity $=1.8 \mathrm{~m} / \mathrm{s}$; longitudinal vibration frequency $=11.95 \mathrm{~s}^{-1}$; side slope $=4.5^{\circ}$; height of riffles $=7 \mathrm{~mm}$ ). 
Considering the results, a very steep side slope resulted in a decrease of the total efficiency of separation (Fig. 7). This was due to the fact, that an increase in the side slope tended to decrease the residence time of plastic flakes on the deck and discharge more PVC flakes to the left-hand compartment of the collecting bin contaminating the light fraction of PP (Table V). Reduction of the side slope, conversely, enhanced the separation by increasing the residence time of plastic flakes on the deck. However, a side slope lower than $2.5^{\circ}$ made the sliding or rolling motion of flakes difficult and worsened the total efficiency of separation (Fig. 7). Therefore, side slope should be set to the minimum, at which it is possible to obtain good distribution of material on the deck of the air table. The experimental results suggested that a side slope of $2.5^{\circ}$ is appropriate for achieving the highest separation efficiency (Fig. 7).

The surface plot and distribution of the contour lines of the variation in total separation efficiency as a function of the end slope and side slope are shown in Fig. 8. These are three-dimensional representations of the experimental data that are displayed with combination of 'end slope', 'side slope' and 'total separation efficiency' values. Contours define the lines of constant 'total separation efficiency' or, in other words, the lines of constant value of total efficiency, across the extent of the end slope and side slope values.

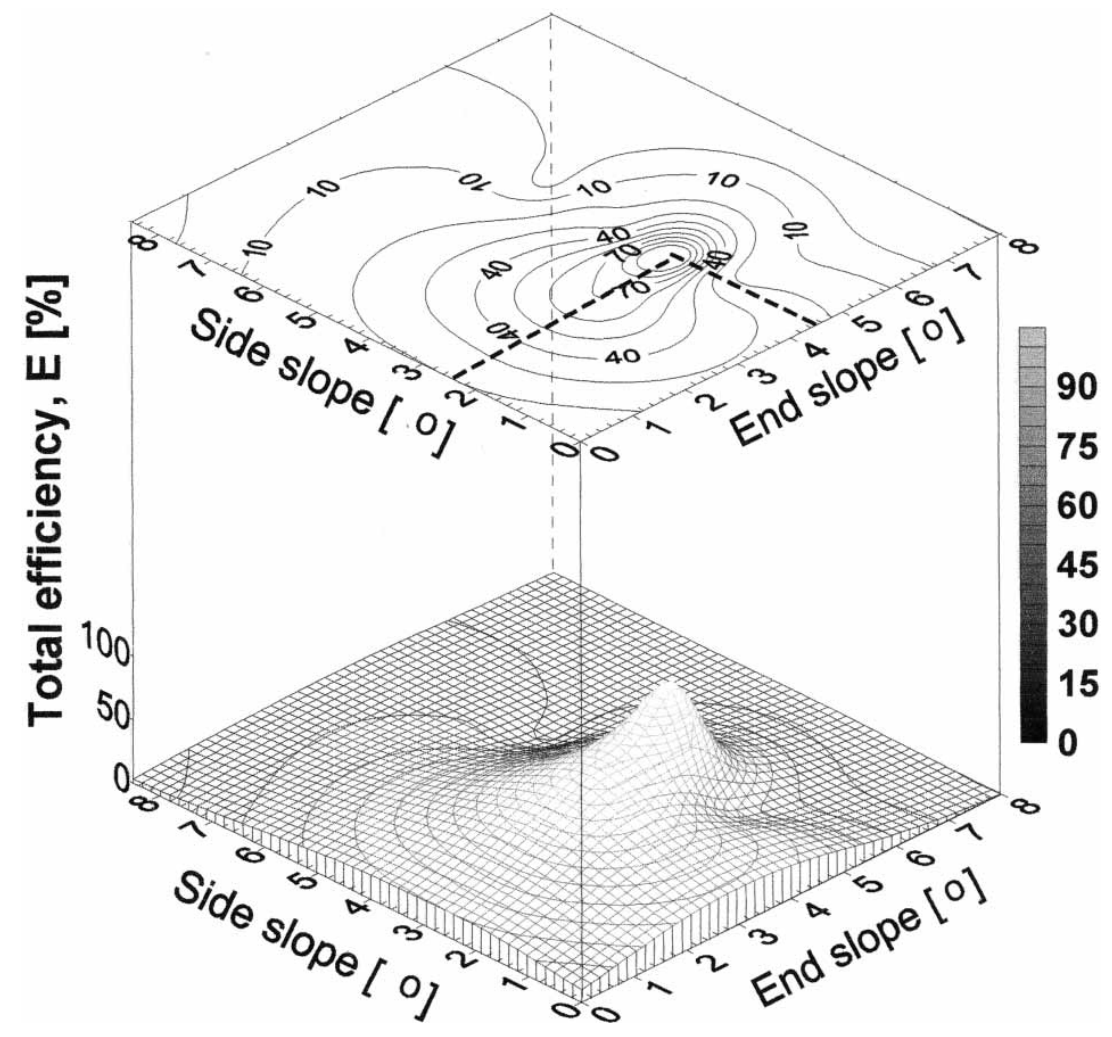

FIGURE 8 Surface plot (at the bottom) and contour lines (at the top) of variation of total efficiency as function of end slope and side slope of the deck (Experimental conditions: PVC/PP mixture (50/50\%); flake size $=-3.36+2.38 \mathrm{~mm}$; superficial air velocity $=1.8 \mathrm{~m} / \mathrm{s}$; longitudinal vibration frequency $=11.95 \mathrm{~s}^{-1} ;$ height of riffles $=7 \mathrm{~mm})$. 
The results plotted in Fig. 8 interpret graphically the data depicted in Figs. 6 and 7, demonstrating that changes in the side slope and particularly in the end slope have a pronounced influence on the total separation efficiency of $\mathrm{PVC} / \mathrm{PP}$ mixture. Moreover, it can clearly be seen that the total efficiency reaches its peak, while the end slope and side slope are set up at $4.5^{\circ}$ and $2.5^{\circ}$ respectively (Fig. 8).

\subsection{The Influence of The Height of The Riffles}

The last studied variable is a construction parameter of the design, namely the height of the riffles. Hence, the porous deck is fitted with riffles of $4.5,7.0$ or $10.0 \mathrm{~mm}$ height respectively, and the experiments are carried out at superficial air velocity of $1.8 \mathrm{~m} / \mathrm{s}$; longitudinal vibrating frequency of $11.95 \mathrm{~s}^{-1}$; end slope, $4.5^{\circ}$; side slope, $2.5^{\circ}$.

The ways in which the separation results of PP from PVC are affected as the height of riffles is varied are recorded in Table VI. The variation of the total separation efficiency of PVC/PP mixture with changes of the height of riffles is shown in Fig. 9. It is

TABLE VI Separation results of PP from PVC. Height of riffles the variable (Experimental conditions: PVC/PP mixture $(50 / 50 \%)$; flake size $=-3.36+2.38 \mathrm{~mm}$; superficial air velocity $=1.8 \mathrm{~m} / \mathrm{s}$; longitudinal vibrating frequency $=11.95 \mathrm{~s}^{-1}$; end slope $=4.5^{\circ}$; side slope $=2.5^{\circ}$ )

\begin{tabular}{lcccccc}
\hline Test no. & $\begin{array}{c}\text { Height of } \\
\text { riffles } \\
{[\mathrm{mm}]}\end{array}$ & $\begin{array}{c}\text { PP fraction } \\
\text { left-hand compartment }\end{array}$ & & \multicolumn{2}{c}{$\begin{array}{c}\text { PVC fraction } \\
\text { right-hand compartment }\end{array}$} \\
\cline { 3 - 4 } & & Grade $[\%]$ & Recovery [\%] & & Grade [\%] & Recovery [\%] \\
\hline 106 & 4.5 & 83.85 & 85.12 & & 73.47 & 53.75 \\
110 & 7.0 & 95.84 & 96.70 & & 99.90 & 97.70 \\
107 & 10.0 & 97.49 & 91.42 & & 97.09 & 97.06 \\
\hline
\end{tabular}

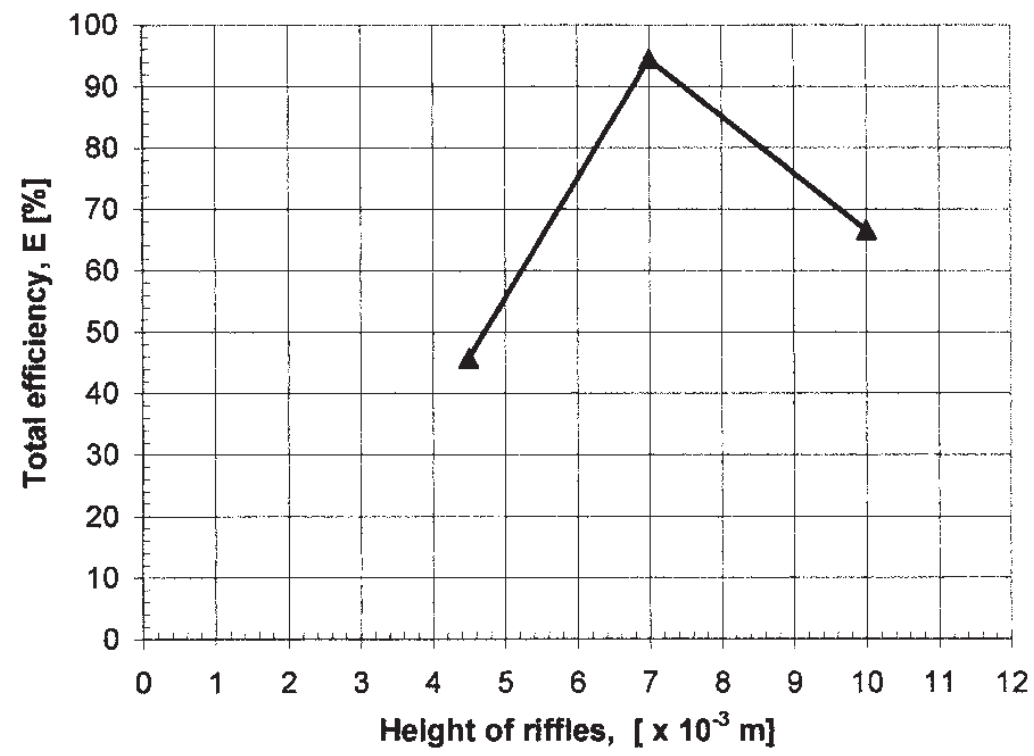

FIGURE 9 Total separation efficiency of PVC/PP mixture (50/50\%), showing the effect of height of riffles (Experimental conditions: flake size $=-3.36+2.38 \mathrm{~mm}$; superficial air velocity $=1.8 \mathrm{~m} / \mathrm{s}$; longitudinal vibrating frequency of the deck $=11.95 \mathrm{~s}^{-1}$; end slope $=4.5^{\circ}$; side slope $=25^{\circ}$ ). 
TABLE VII Optimized operating parameters of air table and experimental results based on numerous tests for separation of PVC/PP plastic mixture

\begin{tabular}{lc}
\hline Plastic mixture & PVC/PP $(50 / 50 \%)$ \\
Flake size [mm] & $-3.36+2.38$ \\
Superficial air velocity [m/s] & 1.8 \\
Longitudinal vibrating frequency of the deck $\left[\mathrm{s}^{-1}\right]$ & 11.95 \\
End slope [ $\left.{ }^{\circ}\right]$ & 4.5 \\
Side slope [ $\left.{ }^{\circ}\right]$ & 2.5 \\
Height of riffles [mm] & 7.0 \\
Total efficiency of separation [\%] & 94.46 \\
Grade of PVC [\%] & 99.90 \\
Grade of PP [\%] & 95.84 \\
Recovery of PVC [\%] & 97.70 \\
Recovery of PP [\%] & 96.70 \\
\hline
\end{tabular}

apparent from examination of Table VI and Fig. 9 that the deck with riffles of $7.0 \mathrm{~mm}$ high ensures higher total efficiency than the one with riffles of $4.5 \mathrm{~mm}$ high. This is due to the fact that riffles of $7.0 \mathrm{~mm}$ height are suitable to retain more "heavier flakes", PVC, on the deck, thus insuring their movement towards the higher side and at the same time prevent them from reporting to the left-hand compartment of the collecting bin (Fig. 2). However, at the given experimental conditions, riffles higher than $7.0 \mathrm{~mm}$ (i.e. $10.0 \mathrm{~mm}$ ) retain also the "lighter flakes", i.e. PP. In turn, the total efficiency decreases as the recovery of PP fraction and grade of PVC fraction also decrease respectively (Table VI, Fig. 9). Considering the results, riffles $7.0 \mathrm{~mm}$ high are suitable to be employed for separation of this specific plastic mixture (Table VI, Fig. 9).

Finally, Table VII summarizes the optimized operating parameters of the air table and the separation results based on numerous tests for separation of the PVC/PP mixture. Once again, it is important to state that only two fractions were produced from the discharged product stream of air table. If a middling, i.e. a third fraction, is collected and re-cycled, a considerable improvement in separation results will result.

\section{CONCLUSIONS}

The objective of this contribution was to investigate the separation performance of the air table when separating a mixture (i.e. PVC/PP plastic mixture) with difference in specific gravity of its components, which are otherwise of the similar size and shape. Evaluations of the separation performance are made in terms of the total efficiency, grade, and recovery.

Our results have indicated the importance of a careful control of the following operating variables, in order to obtain satisfactory performance of the air table when separating PVC/PP mixture.

1. The superficial air velocity, since appropriate velocity lifted the "lighter flakes", PP, up on whereas the "heavier flakes", PVC, remained settled on the deck. Better separation efficiency of a PVC/PP mixture can be obtained at superficial air velocity higher than the minimum fluidizing velocity of its lighter component.

2. The longitudinal vibrating frequency of the deck, since sufficient increase in the vibrating frequency tended to direct the "heavier flakes" that are closest to the deck, to the higher side of the deck. 
3. The end slope, since the observed changes in the end slope indicated that it affected, to a large extent, the direction of travel of the flakes in contact with the deck surface.

4. The side slope, since changes in the side slope affected the residence time of the material on the deck.

5. The height of riffles, since the riffles of appropriate height are suitable to retain the "heavier flakes" on the deck, thus insuring their movement towards the higher side. The performance of the laboratory-scale air table is improved by increasing the height of riffles laid on the porous deck from 4.5 to $7 \mathrm{~mm}$.

Finally, taking into consideration the results of this article, the PVC/PP mixture can selectively be separated using the air table. Based on numerous tests for separation of PVC/PP mixture the optimized operating parameters of the air table are as follows: superficial air velocity of $1.8 \mathrm{~m} / \mathrm{s}$; longitudinal vibrating frequency of $11.95 \mathrm{~s}^{-1}$; end slope, $4.5^{\circ}$; side slope, $2.5^{\circ}$; and riffles, $7 \mathrm{~mm}$ in height. Products of PVC and PP with a grade of 99.90 and $95.84 \%$ respectively have been achieved with recoveries higher than $96.70 \%$. The total efficiency of separation was $94.46 \%$.

\section{NOMENCLATURE}

$d_{p}=$ diameter of particle based on screen analysis [m]

$d_{p}^{*}=$ a measure of particle size [dimensionless]

$E=$ total efficiency of separation $[\%]$

$g=$ acceleration due to gravity $\left[\mathrm{m} / \mathrm{s}^{2}\right] ; g=9.81 \mathrm{~m} / \mathrm{s}^{2}$

$u_{m f}=$ superficial velocity of air at minimum fluidizing conditions $[\mathrm{m} / \mathrm{s}]$

$u_{t}=$ terminal velocity of the particle $[\mathrm{m} / \mathrm{s}]$

$u_{t}^{*}=\mathrm{a}$ measure of terminal velocity [dimensionless]

$\mu=$ absolute viscosity of air [Pa s]; $\mu=1.8 \times 10^{-5} \mathrm{~Pa} \mathrm{~s}$

$\rho_{g}=$ density of air $\left[\mathrm{kg} / \mathrm{m}^{3}\right] ; \rho_{g}=1.29 \mathrm{~kg} / \mathrm{m}^{3}$

$\rho_{\mathrm{PP}}=$ density of PP flake $\left[\mathrm{kg} / \mathrm{m}^{3}\right]$

$\rho_{\text {PVC }}=$ density of PVC flake $\left[\mathrm{kg} / \mathrm{m}^{3}\right]$

$\rho_{s}=$ density of particle $\left[\mathrm{kg} / \mathrm{m}^{3}\right]$

$\phi_{s}=$ sphericity of particle [dimensionless]

\section{Acknowledgments}

The authors gratefully acknowledge and gently appreciate very valuable technical support of Dr. Y. Akagami of Akita Prefecture Industrial Technology Center.

\section{References}

[1] Asaihi Shinbun, Japan Almanac 2002, pp. 163.

[2] F.S. Jr. Kaufman, Opportunities for plastics in resource recovery, Resource Recovery and Utilization, ASTM STP 592, American Society for Testing Materials, 1975, pp. 122-131.

[3] K. Saitoh, I. Nagano and S. Izumi, New Separation technique for waste plastics, Resource Recovery and Conservation, 2 (1976), 127-145.

[4] J. Shibata, S. Matsumoto, H. Yamamoto, E. Kusaka and Pradip, Flotation separation of plastics using selective depressants, Int. J. Min. Process., 48 (1996), 127-134. 
[5] J. Drelich, T. Payne, J.H. Kim and J.D. Miller, Selective froth of PVC from PVC/PET mixtures for the plastics recycling industry, Polymer Eng. Sci., 38 (1998), 1378-1386.

[6] H. Shen, E. Forssberg and R.J. Pugh, Selective flotation separation of plastics by chemical conditioning with methyl cellulose, Resource Conserv. Recy., 35 (2002), 229-241.

[7] J. Shimoiizaka, A. Kounosu, Y. Hayashi and K. Saito, A new type sink-float separator for waste plastics, J. Min. Metall. Inst. Japan, 92 (1976), 675-679, (in Japanese).

[8] G. Dodbiba, N. Haruki, A. Shibayama, T. Miyazaki and T. Fujita, Combination of sink-float separation and flotation technique for purification of shredded PET-bottle from PE or PP flakes, Int. J. Min. Process., 65 (2002), 11-29.

[9] Y. Matsushita, N. Mori and T. Sometani, Electrostatic separation of plastics by friction mixer with rotary drum blades, Elect. Eng. Japan, 127(3) (1999), 33-40.

[10] G. Dodbiba, A. Shibayama, T. Miyazaki and T. Fujita, Electrostatic separation of the shredded plastic mixtures using a tribo-cyclone, Magn. Electr. Sep., 11 (2002), 63-92.

[11] I.I. Inculet and G.S.P. Castle, Triboelectrification of commercial plastic in air, Inst. Phys. Conf. Ser. No. 118: Section 4, paper presented at Electrostatics, 91 (1991), pp. 217-222.

[12] T. Fujita, Y. Kamiya, N. Shimizu and T. Tanaka, Basic study of polymer particles separation using vibrating feeder and electrostatic high voltage generator, Proc. 3rd Int. Sym. East Asian Res. Recycl. Technol., 1995, pp. 155-164.

[13] R.W. Arms, Dry cleaning of coal, Trans. Amer. Inst. Min. Metall. Eng., 70 (1924), 758-774.

[14] E.A. Knapp, Concentrating ores by pneumatic tables. Recent development in mineral dressing, IMM Symp. by 23-25 September 1952, Imperial College of Science and Technology, London, 1953, pp. 299-311.

[15] R.O. Burt, Gravity Concentration Technology, Elsevier Science Publishers B.V., Amsterdam, 1984, pp. 352-372.

[16] E. Canning, Dry mineral sand separation plants of Associated Mineral Consolidates Ltd., New South Wales and Queensland, Min. Metall. Pract. Australia, 10 (1980), 758-761.

[17] S.B. Hudson, Air tabling of beach sand non-conductors for zircon recovery, Proc. Australian Inst. Min. Metall., 204 (1962), 81-108.

[18] K.C. Appleyard, Dry cleaning of coal in England, Trans. Am. Inst. Mining Met. Engrs., 94 (1931), 235-266.

[19] R.L. Llewellyn, Pneumatic cleaning of fine coal for sulfur reduction, 3rd Symposium on Coal Preparation, NCA/BCR conference, Oct. 1977, pp. 123-136.

[20] W.C. McCulloch, R.L. Llewellyn, K.H. Humphereys and J.W. Leonard, Dry Concentration at Coal Preparation (David R. Mitchell Ed.), Seeley W. Mudd Series, 1950, pp. 11.3-11.20.

[21] W.X. Osborn, Tabling tungsten ore without water, Eng. Min. J., 123 (1927), 287-289.

[22] B.A. Wills, Mineral Processing Technology, 6th Edn., Butterworth-Heinemann, Oxford, 1997, pp. 228232.

[23] R. Sivamohan and E. Forssberg, Principle of tabling, Int. J. Miner. Process., 15 (1985), 281-295.

[24] K.P. Galvin and S.J. Pratten, Application of fluidization to obtain washability data, Miner. Engin., 12 (1999), 1051-1058.

[25] D. Kunii and O. Levenspiel, Fluidization Engineering, 2nd Edn., Butterworth-Heinemann, Oxford, 1991, pp. $68-83$

[26] A. Haider and O. Levenspiel, Drag coefficient and terminal velocity of spherical and nonspherical particles, Powder Technol., 58 (1989), 63-70.

[27] A.S. Foust, L.A. Waenzel, C.W. Clump, L. Maus and L.B. Andersen, Principles of Unit Operations, 2nd Edn., John Wiley and Sons Inc., New York, 1980, pp. 711.

[28] E. Douglas, Derivation of a basic efficiency formula for concentrating operation, Trans. Inst. Metall., 71 (1962), 697-704.

[29] N.F. Schulz, Separation efficiency, Transaction SME-AIME, 247 (1970), 81-87.

[30] K. Rietema, On the efficiency in separating mixtures of two constituents, Chem. Engin., 7 (1957), 89-96.

[31] W.A. Worrell and P.A. Versilind, Testing and Evaluation of air classifier performance, Resource Rec. Conserv., 4 (1979), 247-259. 